\title{
Effective hydrogen gas sensor based on palladium nanoparticles dispersed on graphene sheets by spin coating technique
}

\author{
SaOWAluk InPaeng ${ }^{1}$, Worawut Muangrat ${ }^{2}$, KARAKed Tedsree $^{3}$, Wolfgang Pfeiler $^{4}$, \\ ThanaweE ChODJARUSAWAD ${ }^{1}$, ChaisaK ISSRO ${ }^{1, *}$ \\ ${ }^{1}$ Department of Physics, Faculty of Science, Burapha University, Chonburi 20131, Thailand \\ ${ }^{2}$ Materials Engineering Program, Office of Education, Faculty of Engineering, Burapha University, Chonburi 20131, Thailand \\ ${ }^{3}$ 2Department of Chemistry, Faculty of Science, Burapha University, Chonburi 20131, Thailand \\ ${ }^{4}$ Dynamics of Condensed Systems, Faculty of Physics, University of Vienna, Vienna 1090, Austria
}

\begin{abstract}
A room-temperature hydrogen gas $\left(\mathrm{H}_{2}\right)$ sensor was successfully fabricated by dispersion of palladium nanoparticles (Pd NPs) on graphene sheets (GRs) (hereafter referred to as "Pd NPs/GRs"). GRs and Pd NPs were synthesized by chemical vapor deposition technique and by polyol process, respectively. A colloidal solution of Pd NPs with an average diameter of $11 \mathrm{~nm}$ was then dispersed onto the GRs by spin coating technique. The density of dispersed Pd NPs on GRs was controlled by varying the volume of the dispersed solution within the range of $50-150 \mu \mathrm{L}$. The fabricated Pd NPs/GRs sensors exhibited a high sensitivity for $\mathrm{H}_{2}$ gas with a concentration of $1500-6000 \mathrm{ppm}$ at room temperature. Upon $\mathrm{H}_{2}$ exposure, the Pd NPs/GRs sensors showed an increase in electrical resistance, which could easily be measured. The relationship between sensor response and $\mathrm{H}_{2}$ concentration is in correspondence with the Langmuir adsorption model. The $\mathrm{H}_{2}$ detection limit is estimated to be 1 $\mathrm{ppm}$. The results demonstrate that the Pd NPs/GRs sensor is an easily fabricated, but very effective means for room-temperature detection of $\mathrm{H}_{2}$ at ppm level.
\end{abstract}

Keywords: hydrogen gas sensor; graphene sheets; palladium nanoparticles

\section{Introduction}

Hydrogen $\left(\mathrm{H}_{2}\right)$ gas is a colorless, odorless and explosive gas. The flammability of $\mathrm{H}_{2}$ is in the range of $4-75 \%$ in air $[1,2] . \mathrm{H}_{2}$ gas has been used for various sorts of industrial application such as energy storage and transportation. The detection of $\mathrm{H}_{2}$ gas at low concentration is therefore very important to ensure safety. Currently, commercial metal oxide semiconductor materials are widely used to detect $\mathrm{H}_{2}$ gas [3-6]. However, $\mathrm{H}_{2}$ sensors based on metal oxide semiconductors can only be operated above $200{ }^{\circ} \mathrm{C}$ to maintain optimal sensitivity, which is connected with a high-power consumption. A practical sensor, instead, should be operated at room temperature with low-power consumption.

*E-mail: chaisak@buu.ac.th
Recently, graphene [7] has attracted attention due to its structural, mechanical and electrical properties [8,9]. Graphene has been widely used in nanoelectronic devices, especially in gas sensors due to its high surface area, which provides a large gas adsorption capacity [10]. To enhance the sensitivity for $\mathrm{H}_{2}$ gas, combining metal nanoparticle (NPs)-deposition on graphene is a promising route [11-14]. For example, $\mathrm{H}_{2}$ sensors based on palladium (Pd) NPs decorated on graphene by electron beam evaporation $[11,12,14]$ and thermal evaporation techniques [13] have already been demonstrated. The results showed that the Pd NPsdecorated graphene shows a high response to $\mathrm{H}_{2}$ gas compared to that of pristine graphene. However, this technique is limited by the need of an expensive vacuum system for the decoration with metal NPs.

Here, we report a relatively simple fabrication 
of a hybrid sensor based on dispersed Pd NPs on graphene sheet (GRs) by spin-coating method. Graphene and Pd NPs were synthesized by chemical vapor deposition (CVD) and polyol process, respectively. The effect of the concentration of the Pd NPs dispersed in GRs on the sensitivity for $\mathrm{H}_{2}$ gas at room temperature was investigated. The sensor response of Pd NPs-decorated GRs linearly increased with increasing the square root of $\mathrm{H}_{2}$ concentration. This response can be described in the frame of the Langmuir adsorption model.

\section{Materials and methods}

GRs were synthesized by CVD using copper $(\mathrm{Cu})$ foil $\left(1 \times 4 \mathrm{~cm}^{2}\right)$ as a catalyst substrate at atmospheric pressure. The CVD system was heated to $880{ }^{\circ} \mathrm{C}$ under a flow of mixed $\mathrm{H}_{2}$ and $\mathrm{Ar}$ gases $\left(\mathrm{Ar} / \mathrm{H}_{2}=33 / 300\right.$ standard cubic centimeters per minute $(\mathrm{sccm}))$. Then, a mixture of acetylene $\left(\mathrm{C}_{2} \mathrm{H}_{2}\right)$ and $\mathrm{Ar}$ gas $\left(\mathrm{C}_{2} \mathrm{H}_{2} / \mathrm{Ar}=17 / 300\right.$ $\mathrm{sccm}$ ) was introduced into the CVD system for 5 min to synthesize the GRs. Afterwards, palladium nanoparticles (Pd NPs) were synthesized by the polyol process. Typically, $0.40 \mathrm{~g}$ of $\mathrm{PdCl}_{2}$ and $0.38 \mathrm{~g}$ of polyvinylpyrrolidone (PVP) were dissolved in $1 \mathrm{~mL}$ of $0.1 \mathrm{M}$ hydrochloric acid ( $\mathrm{HCl})$ and $90.0 \mathrm{~mL}$ of ethylene glycol by ultrasonic mixing. Next, the mixed solution was refluxed at $125{ }^{\circ} \mathrm{C}$ for $60 \mathrm{~min}$ and the dark-brown color of colloidal Pd NPs was obtained. After cooling down to room temperature, $\mathrm{Pd}$ nanoparticles were separated by adding acetone and by centrifugation at 7000 rounds per minute (rpm) for $4 \mathrm{~min}$. The obtained Pd nanoparticles were dried under nitrogen atmosphere before redispersion in $15 \mathrm{~mL}$ of ethanol. The morphology and elemental compositions of Pd NPs/GRs were characterized by scanning electron microscopy (SEM: LEO1450 VP) and SEM equipped with an energy dispersive X-ray spectrometer (EDS), respectively. Particle size and shape of Pd NPs were determined by transmission electron microscopy (TEM: Philips, TECNAI 20). The carbon structure and crystallinity of the GRs were analyzed by laser Raman spectroscopy (Renishaw: Invia Reflex) with a laser wavelength of $514.5 \mathrm{~nm}$ and the crystal structure was characterized by X-ray diffraction (XRD: Rigaku SmartLab) using $\mathrm{CuK} \alpha$ with a wavelength of $1.54 \AA$.

To fabricate the gas sensors, the GRs were transferred from the $\mathrm{Cu}$ substrate to a $\mathrm{SiO}_{2} / \mathrm{Si}$ substrate by the following process. Poly(methyl methacrylate) (PMMA)/toluene solution was spun into the GRs at $1000 \mathrm{rpm}$ for $1 \mathrm{~min}$, followed by etching the $\mathrm{Cu}$ by floating in ferric chloride $\left(\mathrm{FeCl}_{3}\right)$ for $120 \mathrm{~min}$. The remaining PMMA/GRs were floated in $2 \% \mathrm{HCl}$ acid for $10 \mathrm{~min}$ to remove the $\mathrm{FeCl}_{3}$ residue, followed by neutralization with distilled water. The PMMA/GRs were then transferred onto the $\mathrm{SiO}_{2} / \mathrm{Si}$ substrate and the PMMA was removed by soaking in acetone at $70{ }^{\circ} \mathrm{C}$ for $60 \mathrm{~min}$. Next, volumes of 50,100 and $150 \mu \mathrm{L}$ of the colloidal solution of Pd NPs were spin-coated onto the GRs at $1000 \mathrm{rpm}$ for $30 \mathrm{sec}$ at room temperature (hereafter referred as Pd NPs (50)/GRs, Pd NPs (100)/GRs and Pd NPs (150)/GRs, respectively). The Pd NPs/GRs sensors fabricated in this way were placed into a stainless steel chamber to detect $\mathrm{H}_{2}$ gas at room temperature with concentration in the range of $1500-6000 \mathrm{ppm}$, controlled by recording their electrical resistance with a multimeter (FLUKE 189). The initial pressure before introducing nitrogen gas $\left(\mathrm{N}_{2}\right)$ was atmospheric pressure. To adjust the baseline of the sensor, $\mathrm{N}_{2}(500$ sccm) was first introduced into the measurement system for $5 \mathrm{~min}$. Then, the $\mathrm{N}_{2}$ gas was replaced by $\mathrm{H}_{2}$ gas for $30 \mathrm{~min}$. To eliminate the $\mathrm{H}_{2}$ gas after the measurement from sensor material, the sensor was heated to $90{ }^{\circ} \mathrm{C}$ under dry air for $10 \mathrm{~min}$, followed by cooling to room temperature for $50 \mathrm{~min}$. The sensor response (in \%) of the Pd NPs/GRs sensors is defined as:

$$
\text { Sensor response } \begin{aligned}
(\%) & =\frac{R_{g a s}-R_{0}}{R_{0}} \times 100 \\
& =\frac{\Delta R}{R_{0}} \times 100
\end{aligned}
$$

where $R_{\text {gas }}$ and $\mathrm{R}_{0}$ are the resistances of $\mathrm{H}_{2}$ and $\mathrm{N}_{2}$ gases, respectively. The response time is defined as the time required until $90 \%$ of the maximum response is reached, while the recovery time is the time needed until the baseline is reached again. The 
schematic view of the sensor measurement system is shown in Fig. 1.

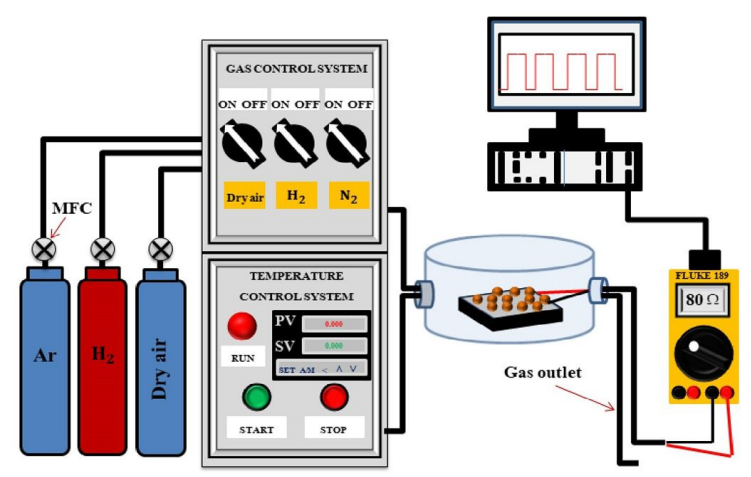

Fig. 1. Schematic view of the gas sensor measurement system.

\section{Results and discussion}

Fig. 2a shows the Raman spectrum of the GRs on the $\mathrm{Cu}$ foil. The GRs exhibit D-band (disordered structural defect), G-band (graphitic-structure) and 2D-band (graphitic-structure) peaks at 1345, 1587 and $2700 \mathrm{~cm}^{-1}$, respectively. The $\mathrm{I}_{2 \mathrm{D}} / \mathrm{I}_{\mathrm{G}}$ intensity ratio is about 0.68 , which indicates that the synthesized GRs are multilayer graphene sheets $[15,16]$. The XRD diffraction pattern of Pd NPs/GRs is shown in Fig. 2b. The diffraction peaks of the Pd NPs/GRs at $39.8^{\circ}$ and $46.3^{\circ}$ are characteristic of face-centered cubic $\mathrm{Pd}$ and correspond to the (lll $\left.\begin{array}{lll}1 & 1 & 1\end{array}\right)$ and ( $\left.\begin{array}{lll}2 & 0 & 0\end{array}\right)$ planes, respectively $[17,18]$.

In Fig. 3a, a TEM image of an uniform narrow distribution of Pd NPs with an average diameter of $11.1 \pm 0.02 \mathrm{~nm}$ is shown. The inset of Fig. 3a displays the Gaussian distribution of Pd NPs sizes. The Pd NPs have diameters mostly in the range of $9-13 \mathrm{~nm}$, centered at $11 \mathrm{~nm}$. In addition, Pd NPs with diameters larger than $13 \mathrm{~nm}$ can be occasionally observed in all the samples. Fig. $3 b$ to Fig. 3d show SEM images of the dispersion and density of Pd NPs on GRs. All samples show a well-dispersed distribution of Pd NPs on GRs. The particle densities of Pd NPs (50)/GRs, Pd NPs (100)/GRs and Pd NPs (150)/GRs are $6 \times 10^{5}$, $8 \times 10^{5}$ and $11 \times 10^{5} \mathrm{~cm}^{-2}$, respectively, which
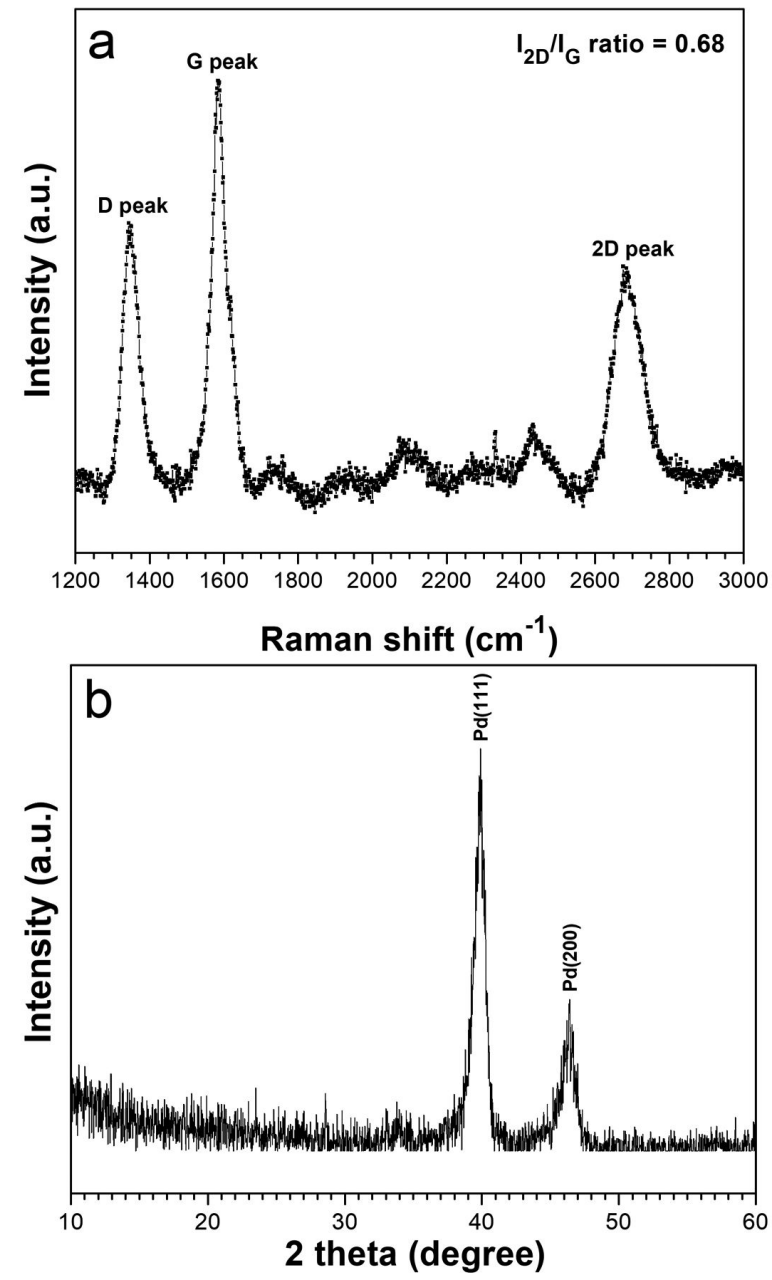

Fig. 2. (a) Raman spectrum of GRs on Cu foil. (b) XRD spectrum of Pd NPs/GRs.

documents that the density of Pd NPs on GRs increases with increasing the volume of dispersed $\mathrm{Pd}$ NPs-solution.

Fig. 4a shows the Pd NPs/GRs sensors response (in \%) to alternating supply of $6000 \mathrm{ppm} \mathrm{H}_{2}$ in air as a function of exposure time for 3 cycles and three particle densities. The electrical resistance of all sensors increased upon $\mathrm{H}_{2}$ exposure and decreased after heating to $90{ }^{\circ} \mathrm{C}$ under dry air and cooling to room temperature. The additional increase of resistivity during heating is due to the positive temperature coefficient, completely reversed during cooling. All the sensors have been recovered to their initial resistance (baseline) by heating for 10 min to $90{ }^{\circ} \mathrm{C}$ under air. The sensor responses (\%) 


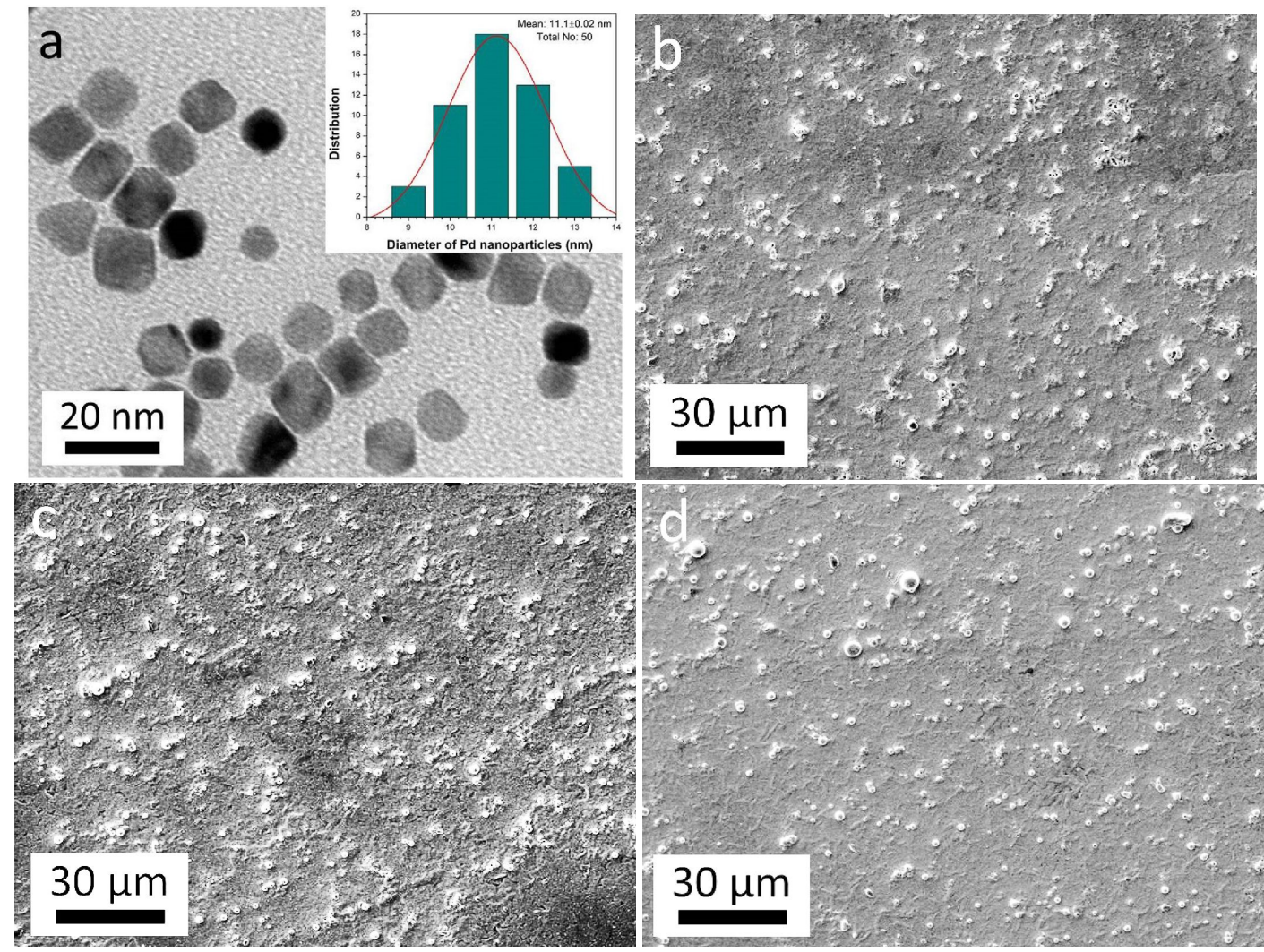

Fig. 3. (a) TEM image of Pd NPs (inset: Gaussian distribution of Pd NPs sizes). (b), (c), (d) SEM images of Pd NPs (50)/GRs, Pd NPs (100)/GRs and Pd NPs (150)/GRs, respectively.

of Pd NPs (50)/GRs, Pd NPs (100)/GRs and Pd NPs (150)/GRs were $1.57 \%, 2.26 \%$ and $2.77 \%$, respectively. The Pd NPs (150)/GRs showed the highest response to $\mathrm{H}_{2}$ gas as compared to Pd NPs (50)/GRs and Pd NPs (100)/GRs due to the highest density of Pd NPs on GRs (Fig. 3(d)). Obviously, the higher density of Pd NPs provides more active sites, resulting in a higher response. The sensor response (\%) of Pd NPs (150)/GRs as a func-

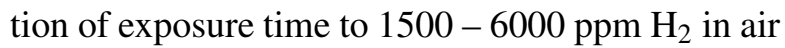
is shown in Fig. 4b. The sensor responses at 1500, 3000,4500 and $6000 \mathrm{ppm}$ were $0.84,1.66,2.04$ and $2.77 \%$, respectively. Fig. $4 \mathrm{c}$ shows the sensor response of Pd NPs (150)/GRs as a function of square root of $\mathrm{H}_{2}$ concentration in the range of $1500-$ $6000 \mathrm{ppm}$. The sensor response (\%) increases linearly with the square root of $\mathrm{H}_{2}$ concentration. Therefore, the relation between sensor response (\%) and gas concentration is based on the Langmuir adsorption isotherm model [12, 19]. During
$\mathrm{H}_{2}$ exposure, $\mathrm{H}_{2}$ adsorbed on the Pd NPs surface is dissociated into $2 \mathrm{H}$; the process of adsorption is then the reaction between the gas molecule and two surface sites. At equilibrium, the adsorption isotherm can be explained as:

$$
\begin{gathered}
k_{a} \cdot P \cdot(1-\theta)^{2}=k_{d} \cdot \theta^{2} \\
\frac{\theta}{1-\theta}=(K \cdot P)^{1 / 2}
\end{gathered}
$$

where $\mathrm{k}_{\mathrm{a}}$ and $\mathrm{k}_{\mathrm{d}}$ denote the adsorption and desorption rate constants, respectively, $\mathrm{K}$ is the equilibrium constant for $\mathrm{H}_{2}$ dissociative adsorption, $\mathrm{P}$ the pressure or concentration of $\mathrm{H}_{2}$, and $\theta$ is the coverage of atomic hydrogen on Pd surface.

The response and recovery times of the Pd NPs (150)/GRs exposed to $1500-6000 \mathrm{ppm} \mathrm{H}_{2}$ are shown in Table 1 . The response time decreases and the recovery time increases with increasing the 


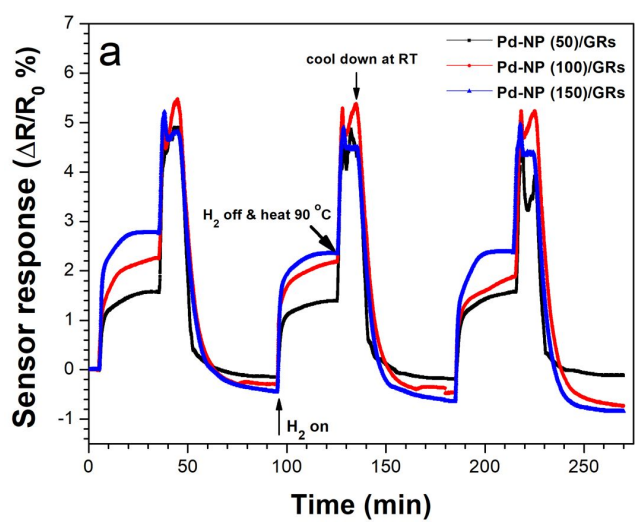

needed during the purging process to remove the $\mathrm{H}_{2}$ molecules, which are attached to the surface of the sensing material.

The limit of detection (LOD) was estimated to be $1 \mathrm{ppm}$ for Pd NPs (150)/GRs [20, 21]. This result demonstrates that the sensor based on $\mathrm{Pd}$ NPs (150)/GRs presented in this paper can be used down to ppm level at room temperature.

(a) Absence of hydrogen

a
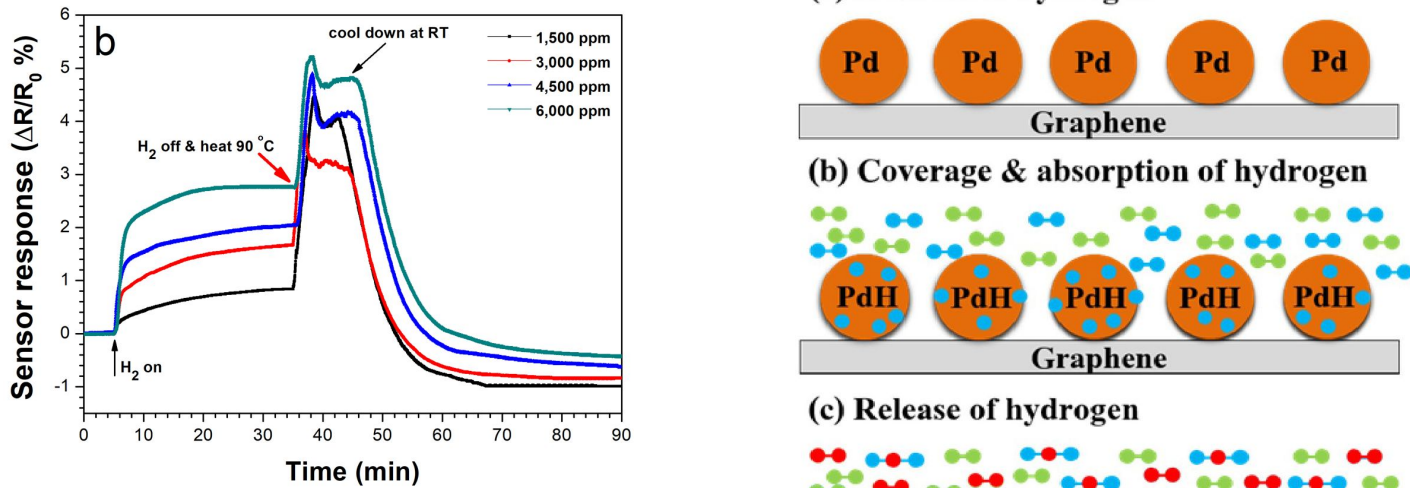

(b) Coverage \& absorption of hydrogen

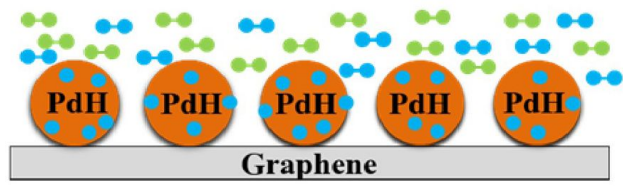

(c) Release of hydrogen
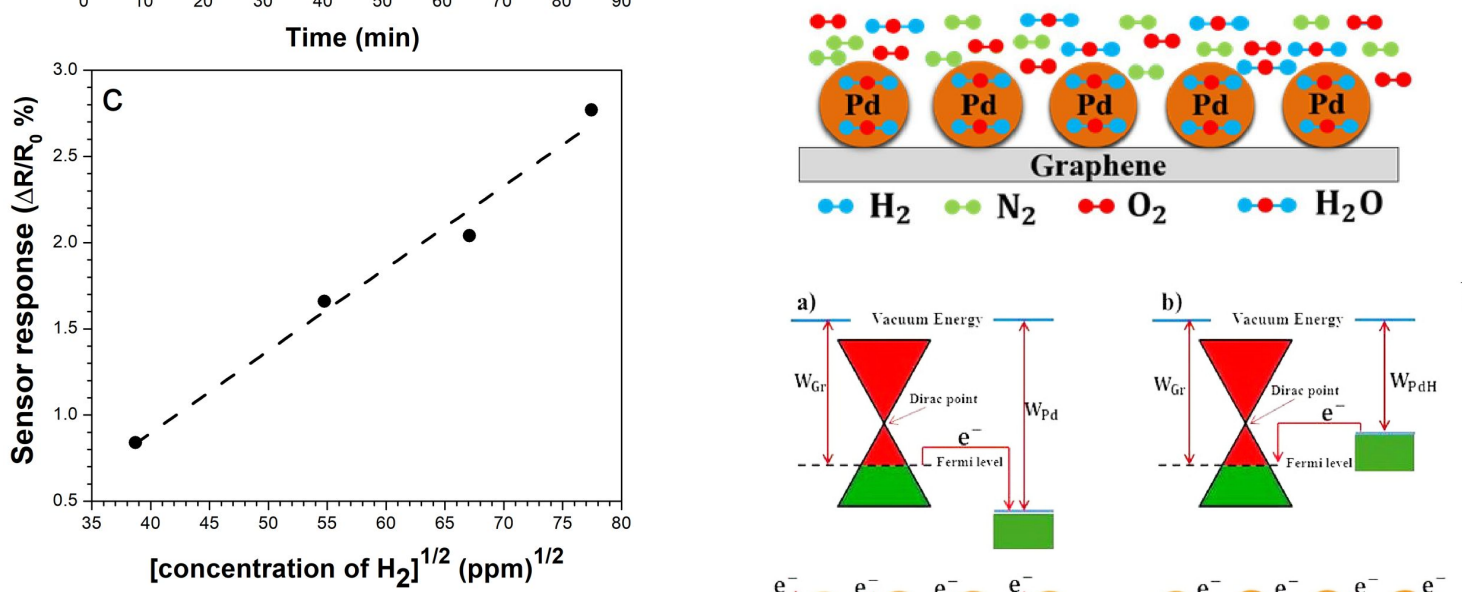

b

Fig. 4. (a) Pd NPs/GRs sensors response (\%) to 6000 ppm $\mathrm{H}_{2}$ as a function of exposure time; (b) $\mathrm{Pd}$ NPs (150)/GRs sensor response (\%) to 1500 $6000 \mathrm{ppm} \mathrm{H}_{2}$ as a function of exposure time; (c) Pd NPs (150)/GRs sensor response as a function of square root of $\mathrm{H}_{2}$ concentration.

concentration of $\mathrm{H}_{2}$ gas. Obviously, the coverage of the sensing material surface with $\mathrm{H}_{2}$ molecules at high concentration is saturated faster than in the case of low concentration, resulting in a decrease of the corresponding response time. On the other hand, at high concentration of $\mathrm{H}_{2}$ more time is

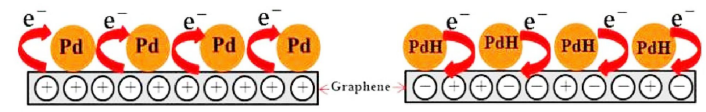

Fig. 5. Energy band of Pd NPs (150)/GRs sensor (a) before and (b) after exposure to $\mathrm{H}_{2}$ gas.

For an explanation of the sensing mechanism the following model has been proposed [12, 13, 22]: The hydrogen molecules adsorbed on the $\mathrm{Pd}$ surface dissociate and diffuse into the bulk $\mathrm{Pd}$ with high solubility, forming $\mathrm{Pd}$ hydride $\left(\mathrm{PdH}_{\mathrm{x}}\right)$. The work function of $\mathrm{PdH}_{\mathrm{X}}$ is lower than that of graphene $(\Phi=4.5 \mathrm{eV})$ and $\operatorname{Pd}(\Phi=5.6 \mathrm{eV})[23]$. Therefore electrons are transferred from $\mathrm{PdH}_{\mathrm{x}}$ to 
Table 1. Response time and recovery time of the Pd NPs (150)/GRs exposed to $1500-6000 \mathrm{ppm}_{2}$.

\begin{tabular}{ccc}
\hline Concentration of $\mathrm{H}_{2}[\mathrm{ppm}]$ & Response time [min] & Recovery time [min] \\
\hline \hline 1500 & 18.46 & 16.42 \\
3000 & 15.39 & 17.00 \\
4500 & 15.13 & 20.42 \\
6000 & 8.19 & 22.57 \\
\hline
\end{tabular}

graphene and the density of mobile p-type charge carriers in graphene decreases, resulting in an increase of electrical resistance of the sensor [12, 22]. During purging by annealing for $10 \mathrm{~min}$ at $90{ }^{\circ} \mathrm{C}$ under dry air atmosphere, the process is reversed: The $\mathrm{PdH}_{\mathrm{x}}$ hydrides are dissolved and electrons are transferred back to Pd from GR due to the lower work function of GR compared to Pd. Thus, the electrical resistance of Pd NPs/GRs decreases to its initial value due to the re-increase of holes in GRs. The schematic view of the sensing mechanism is shown in Fig. 5.

\section{Conclusions}

A very effective $\mathrm{H}_{2}$ gas sensor was successfully fabricated by the dispersion of Pd NPs on GRs with a new spin coating technique. Its detection limit was estimated to go down to $1 \mathrm{ppm}$. For the sensing performance of $\mathrm{H}_{2}$, the density of $\mathrm{Pd}$ NPs on the GRs plays an important role. In correspondence with the Langmuir adsorption isotherm model, the sensitivity of Pd NPs/GRs increases linearly with increasing square root of $\mathrm{H}_{2}$ concentration. The present results demonstrate that the $\mathrm{Pd}$ NPs/GR sensors produced in this relatively simple way by spin coating technique have the potential to be an outstanding element for sensing low concentrations of $\mathrm{H}_{2}$ in air at room temperature.

\section{Acknowledgements}

This work was supported by Faculty of Science, Burapha University and National Research Council of Thailand (NRCT).

\section{References}

[1] https://en.wikipedia.org/wiki/Hydrogen, accessed on: 2018.03.16.

[2] Carcassi M.N., Fineschi F., Energy, 30 (2005), 1439.
[3] Jun Y.K., Kim H.S., LeE J.H., Hong S.H., Sensor Actuat. B-Chem., 107 (2005) 264.

[4] Wang B., Zhu L.F, Yang Y.H., XU N.S., YANG G.W., J. Phys. Chem. C., 112 (2008) 6643.

[5] Kanan S.M., El-Kadri O.M., Abu-Yousef A., KANAn M.C., Sensors-Basel, 9 (2009) 8158.

[6] Gu H., Wang Z., Hu Y., Sensors-Basel, 12 (2012) 5517.

[7] Katsnelson M.I., Mater. Today, 10 (2017), 20.

[8] Novoselev K.S., FAL'Ko V.I., Colombo L., Gellert P.R., Schwab M.G., KIM K., Nature, 490 (2012), 192.

[9] Bechstedt F., Matthes L., Gori P., Pulci O., Appl. Phys. Lett., 100 (2012) 261906.

[10] Geim A. K., Novoselev K.S., Nat. Mater, 6 (2007), 183.

[11] Johnson J.L., Behnam A., Pearton S.J., Ural A., Adv. Mater., 22 (2010), 4877.

[12] Wu W., Liu Z, Jauregui L.A., Yu Q., Pillai R., Cao H., Bao J., Chen Y.P., Pei S.S., Sensor Actuat. B-Chem., 150 (2010), 296.

[13] Chung M.G., KIM D.-H., SeO D.K., KIM T., IM H.U., Lee H.M., Yoo J.-B., Hong S.-H., KANG T.J., KIM Y.H., Sensor Actuat. B-Chem., 169 (2012), 387.

[14] Park Y., Kim S.S., Jeong H., Kang C.G., PARK J.S., Song H., LeE R., Myoung N., LeE B.H., SeO S., Kim J.T., Jung G.Y., ACS Appl. Mater. Inter, 6 (2014) 13293.

[15] Dong X., Wang P., Fang W., Su C.-Y., Chen Y.H., Li L.-J., HuAng W., Chen P., Carbon, 49 (2011), 3672 .

[16] Nguyen V.T., LE H.D., NGuyen V.C., Ngo T.T.T., Le D.Q., Nguyen X.N., Phan N.M., Adv. Nat. Sci.: Nanosci. Nanotechnol., 4 (2013), 035012.

[17] Bai Z., YAng L., Li L., LV J., Wang K., Zhang J., J. Phys. Chem. C., 113 (2009), 10568.

[18] Yang S., Dong J., Yao Z., Shen C., Shi X., Tian Y., LIN S., ZHANG X., Sci. Rep.-UK, 4 (2014), 4501.

[19] WongWiriYapan W., OKabayashi Y., Minami S., ItABASHI K., UEDA T., ShimaZaki R., Ito T., OURa K., Honda S., Tabata H., Katayama M., Nanotechnology, 22 (2011), 055501.

[20] Li J., Lu Y., Ye Q., Cinke M., Han J., Meyyappan M., Nano Lett., 3 (2003), 929. 
[21] Muangrat W., Wongwiriyapan W., Yordsri V., Chobsilp T., InPAEng S., IsSRo C., Domanov O., Ayala P. Pichler T., Shi L., Phys. Status Solidi A., 215 (2018), 1800004.

[22] Kumar R., MaliK S., Mehta B.R., Sensor Actuat. B-Chem., 209 (2015), 919.
[23] Xia F., Perebeinos V., Lin Y.-M., Wu Y., AVOURIS P., Nat. Nanotechnol., 6 (2011), 179.

Received 2018-04-03 Accepted 2019-04-23 